\title{
Performance of Steel Frame with Linkage System under Earthquake Excitation
}

\author{
Guang $\mathrm{Xu}$ \\ Department of Advanced Industrial Science \\ Kumamoto University \\ Kumamoto, Japan \\ xuguang1991@hotmail.com
}

\author{
Minoru Yamanari \\ Faculty of Advanced Science and Technology \\ Kumamoto University \\ Kumamoto, Japan \\ yamanari@kumamoto-u.ac.jp
}

\begin{abstract}
Authors have already proposed a linkage system with rotational friction dampers that can be expected to dissipate seismic energy rather than the main frame. In this paper, the relationship between the rotational angle of the linkage system and inter-story drift angle of a structure was investigated. Consequently, a three-bay twelve-story steel frame with linkage system was analyzed by a numerical simulation program based on a theory of non-linear dynamic analysis. The distribution of slipping moment of friction damper along with the height of the main structure was discussed. Meanwhile, optimal slipping moment range was suggested according to analysis results.
\end{abstract}

\section{Keywords-steel frame; linkage system; friction damper}

\section{INTRODUCTION}

There could be a big increase in the number of tremendous earthquakes around the world in the following years [1]. So far, it is difficult to predict where and when these earthquakes will occur. Therefore, in order to protect people and properties, a number of methods to decrease structure vibration under earthquake excitation have been proposed. These methods/control systems could be divided into four patterns: passive, active, semi-active and hybrid [2]. A passive control system works without requiring an external power source, which is necessary for active and semi-active control system. Generally, passive control system consists of one or more equipment designed to modify the structural properties like ductility and stiffness, causing a reduction in the structure seismic behavior. Friction damper is a typical representative of passive control systems, which is used to dissipate the seismic input energy via solid friction. This type of device was pioneered in 1982 [3]. It is similar to automobile brakes, which use the mechanism of solid friction to dissipate seismic energy reducing the motion of the structure. Commonly, the friction damper is made of a series of special steel plates that are bolted by a high strength screw. Suitable friction pads can be clamped between these steel plates, in order to create frictional performance. Because the clamping force is controlled by a screw, it is very convenient to change the frictional force to satisfy diffident purposes. However, a lower limit value of frictional force is also necessary, as it is not expected for friction damper to slip during a severe wind or earthquake. When the force or moment developing in the friction damper reaches a predetermined value, it will start slipping and keeping a steady status. That is a remarkable feature differing from other dampers, liking viscous damper, oil damper and TMD.

According to the connection with the main structure, friction dampers can be divided into four types: Pall friction damper, Sumitomo friction damper, gap-screw connection damper, and rotational friction damper [4]. Pall friction damper has two friction joints on the upper and down arm-brace, respectively. Four cross braces are used to connect it with the main structure, which are pin connected at both ends. It has been widely used to strengthen the seismic behavior of many structures around the world $[2,5-10]$. It is easily found that the Pall friction damper has only translational movement at the friction joints when it starts slipping [11]. Differing from it, in 2000 the DAMPTECH company presented a rotational friction damper in which the movements are rotational [12]. A common point of all dumpers is that they will dissipate seismic energy to protect structures from damage or collapse. In order to extend the dissipation energy to a maximum value, some researches about optimal friction force or moment have been done [2, 1215]. However, the optimal value of the friction damper in each story is the same with the one of the first story, but, seismic shear force gradually decreases along with the height of the structure. It means that if a same optimal value was used for every damper of each story, it will not get the best seismic performance of the structure because the top dampers will not slip or slip just a little bit. For this reason, the distribution of the optimal value along the height of the structure will be discussed in this paper. On the other hand, the capacity of energy dissipation within a friction damper almost depends on slip displacement and slip force. For the same slip force, if the friction damper slipped on a maximum displacement at each step, the amount of dissipated energy will be increased. Hence, the objectives of this paper are: 1) To propose a linkage system, which will enlarge the slip displacement of friction damper. 2) To discuss the distribution of slipping moment in dampers along the structure height. 3) To find the optimal value for which the best seismic performance of the structure occurs.

\section{LINKAGE SYSTEM}

As mentioned above, the capacity of energy dissipation in the friction damper almost depends on the slip displacement 
and slip force. The proposed mechanism of displacement amplification is shown in Figure 1. It can be regarded as a combination of Pall friction damper and rotational friction damper. The friction joints, which are placed in the center of the side of the quadrangle in Pall friction damper, are removed to its corner. The movement in the linkage system is rotational not translational as in the Pall friction damper. When a tension or compression acts on the corner of the quadrangle, it will be shaped as a parallelogram, and the relative rotational angle can be obtained from the four corner joints. That is the slip displacement of the rotational friction damper. The connections of the other elements to the main structure are the same as in the Pall friction damper. In the linkage system, cross brace is pinned to the main structure and the other end of it is directly connected to the damper. Because the arm braces rotate on the contrary direction, there will be no moment generated in the cross braces like in the ones in Pall friction damper. Therefore, comparing to Pall friction damper, it has a simplified construction in which the number of connection bolts, slip bolts and curve slots has been reduced. Furthermore, instead of translational displacement, rotational displacement is used for energy dissipation.

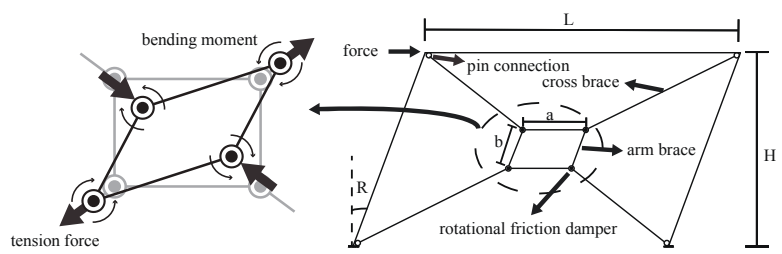

Fig. 1. The conception of linkage system

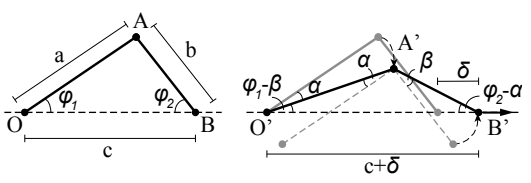

Fig. 2. Geometrical relationshiop

\section{GEOMETRICAL RELATIONSHIP WITH MAIN STRUCTURE}

To identify the mechanism of displacement amplification of the linkage system, the relationship between the rotational angle in the linkage system and the drift angle in the main structure needs to be formulated. In this section, it is assumed that deformation in elements will not be considered. The computation schematic for the half of linkage system is shown in Figure 2, where $a$ and $b$ are the span and height of the linkage system, $c$ is the length of the diagonal line, $\varphi_{1}$ and $\varphi_{2}$ are the inner angles of triangle $A O B, \alpha$ and $\beta$ are the rotational angles, $\delta$ is the increment of diagonal line. Using cosine law, the relationship of $a$ and $\delta$ may be written as:

$$
\cos \left(\varphi_{1}-\alpha\right)=\frac{a^{2}+(c+\delta)^{2}-b^{2}}{2 a(c+\delta)}
$$

Using addition theorem,(1) could be written as:

$$
d \cos \alpha+e \sin \alpha=\frac{a^{2}+(c+\delta)^{2}-b^{2}}{2 a(c+\delta)}
$$

where, $d$ and $e$ are expressed as:

$$
\begin{aligned}
& d=\cos \varphi_{1}=\frac{a^{2}+c^{2}-b^{2}}{2 a c} \\
& e=\sin \varphi_{1}=\sqrt{1-d^{2}}
\end{aligned}
$$

Taylor series expansion is used to simplify the rotational angle $\alpha$ :

$$
d+e \alpha-\frac{1}{2} d \alpha^{2}=\frac{a^{2}+(c+\delta)^{2}-b^{2}}{2 a(c+\delta)}
$$

According to (5), $\alpha$ expressed by $\delta$ could be earned as:

$$
\alpha=\frac{c e+e \delta}{c d+d \delta}-\frac{\sqrt{(a c e+a e \delta)^{2}-(a c d+a d \delta) x_{1}}}{(a c d+a d \delta)}
$$

in which, $x_{1}$ is expressed as:

$$
x_{1}=\left(a^{2}-b^{2}+c^{2}-2 a c d+2 c \delta-2 a d \delta+\delta^{2}\right)
$$

Using the same method, the other rotational angle $\beta$ could be expressed as:

$$
\beta=\frac{c g+g \delta}{c f+f \delta}-\frac{\sqrt{(b c g+b g \delta)^{2}-(b c f+b f \delta) x_{2}}}{(b c f+b f \delta)}
$$

where, $x_{2}$ is:

$$
x_{2}=\left(-a^{2}+b^{2}-c^{2}-2 b c f+2 c \delta-2 b f \delta+\delta^{2}\right)
$$

Then, the relative rotational angle of damper could be written as:

$$
\varphi=\alpha+\beta
$$

Using (1)-(10), the relationship between the damper relative rotational angle and the increment of quadrangle diagonal line could be obtained. In addition, the relationship between the drift angle of main structure and the increment of diagonal line of quadrangle is necessary. It is assumed that main structure deforms as shown in Figure 3, where $H$ is the height of main structure, $L$ is the length of the span, and $R$ is the drift angle. Therefore, the increment of diagonal line of quadrangle could be expressed as:

$$
\delta=\sqrt{\mathrm{H}^{2}+(L+H R)^{2}}-\sqrt{H^{2}+L^{2}}
$$

Using (10)-(11), the relationship between the damper's relative rotational angle and the main structure's drift angle can be obtained. To examine the accuracy of equations, numerical analysis is necessary. Program OpenSees based on the finite element method is used to simulate the numerical example. The model shown in Figure 1 is used for the analysis, where the lengths of arm braces $a$ and $b$ are $1.4 \mathrm{~m}$ and $0.7 \mathrm{~m}$ respectively, and height and span of structure are $3.5 \mathrm{~m}$ and $7 \mathrm{~m}$ respectively. The beam is assumed infinitely rigid and the columns are fixed at their bases. The steel columns are wide-flange sections with the moment of inertia of $3.4 \times 10^{-5} \mathrm{~m}^{4}$. The sectional area of the brace is $4 \times 10^{-3} \mathrm{~m}^{2}$ and the slipping moment of damper is set as 
$20 \mathrm{Nm}$. The dead load is assumed as $392 \times 10^{3} \mathrm{~N}$ and the critical damper ratio is $5 \%$. Newmark- $\beta(\beta=0.25)$ method is adopted for the numerical integration. The comparison between the approximate value obtained by the equations and the geometrical exact value obtained by OpenSees is shown in Figure 4 . The results indicated that the accuracy of equations is very high in normal range (i.e. $R \leq 0.06$ ).

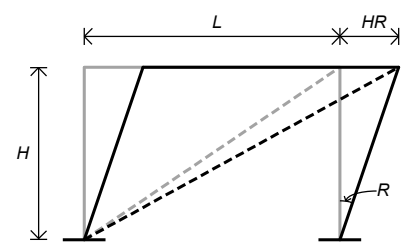

Fig. 3. Structure deformation

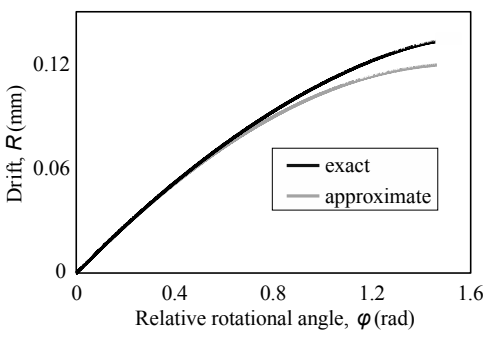

Fig. 4. Accuracy of equations

\section{FINITE ELEMENT ANALYSIS}

\section{A. Finite Element Modeling}

For discussing the distribution of friction force in the damper along the height of main structure, two models are created by SAP2000, as shown in Figure 5. Their difference will be introduced below. Both are the models of a 12-story two-dimensional structure with $7 \mathrm{~m}$ span lengths and a height of $3.5 \mathrm{~m}$, with 3 openings. Supports are assumed to be fixed and the soil structure interaction effects are neglected. Dead and live loads are concentrated mass at the beam-to-column node. The sections of the main structure, shown in Table I, are made from SN490 (based on JIS standard). The plastic behavior of elements in main structure is considered by simple hinges based on TABLES 9-6 IN ASCE 41-13 [16], which are assigned to both ends of the elements. The cross braces and arm members should be considered strong enough to remain elastic during earthquakes. These elements are selected from circular cross section cables and beam element, respectively. Meanwhile, the ratio of initial stiffness of the linkage system to one of the main structures is set as 1.0. In order to modify friction damper in linkage system, plastic-Wen element is used in SAP2000. The friction behavior is considered in R3 direction and the other directions are fixed. A yielding exponent of 10 indicating a sharp transition from linear to plastic phase and a post yield stiffness ratio of 0.0001 indicating a rectangular hysteresis loop are used to simulate the friction behavior of dampers [14]. The details of the damper model are shown in Figure 6. In addition, P- $\Delta$ effects are included to account for the geometrical nonlinearity effects and out-of-plane distortion of all elements is not considered.

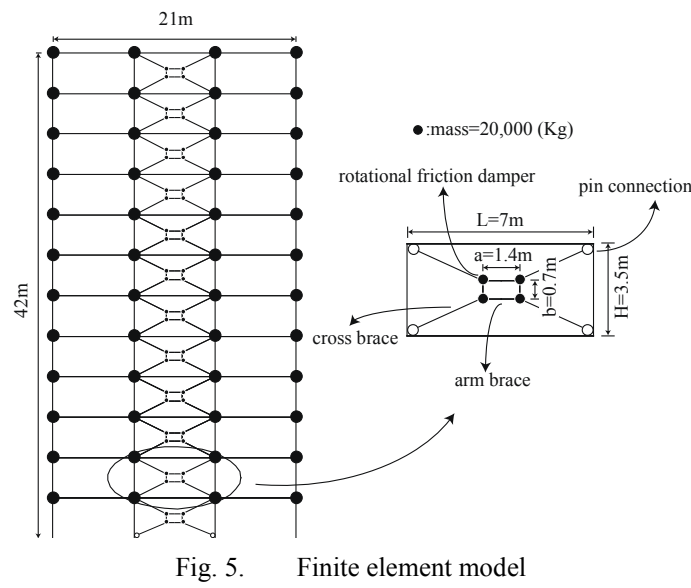

TABLE I. THE SECTION USED IN MAIN STRUCTURE

\begin{tabular}{|c|c|c|}
\hline Story No. & Column & Beam \\
\hline $10-12$ & $500 \times 500 \times 19$ & $450 \times 250 \times 12 \times 28$ \\
\hline $7-9$ & $500 \times 500 \times 22$ & $500 \times 300 \times 16 \times 25$ \\
\hline $4-6$ & $500 \times 500 \times 25$ & $550 \times 300 \times 16 \times 28$ \\
\hline $1-3$ & $500 \times 500 \times 28$ & $600 \times 250 \times 16 \times 32$ \\
\hline
\end{tabular}

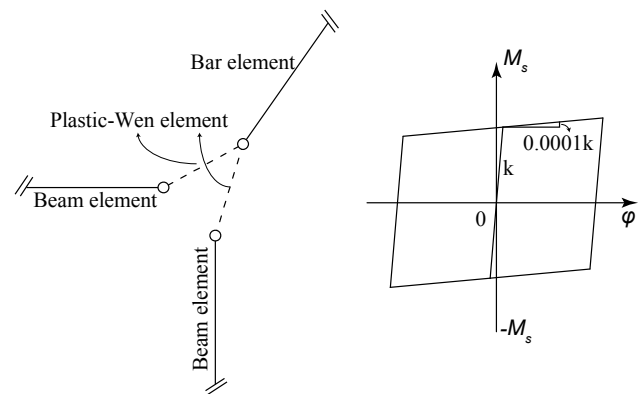

Fig. 6. Damper model and hysteretic curve

\section{B. Analysis Conditions and Methods}

In this analysis, the damping of the model is considered as a Rayleigh damping. First-order and second-order damping coefficients are both $2 \%$. Newmark- $\beta$ method with $\beta=0.25$, $\alpha=0.5$ is used to analyze the model. The output time step size is set at $0.001 \mathrm{~s}$ and seismic duration is $40 \mathrm{~s}$. Four observed seismic waves, shown in Table II, are used in nonlinear time history analysis. In order to observe the seismic behavior of the structure equipped with a linkage system under a tremendous earthquake, the peak ground velocity (PGV) of each wave is scaled to $1.0 \mathrm{~m} / \mathrm{s}$. The input direction of seismic waves is horizontal. For determining the slipping moment of friction damper, slipping moment ratio $A s$ is defined as:

$$
A_{s}=\frac{M_{s i}-M_{s i 1}}{M_{s i 2}-M_{s i 1}}
$$

where $M_{s i}$ is the slipping moment of friction damper in the $i$-th story, $M_{s i l}$ is a moment, which is generated in friction damper of the $i$-th story when a group of forces (base shear force $=0.2 \mathrm{~g}$ ) according to $A_{i}$ distribution [17] were imposed on the structure and friction damper did not slip. In the same way, when the forces equating to the held horizontal yield strength of structure 
[17] were imposed on the structure, the generated moment in $i$ th story is determined as $M_{s i 2}$. In this analysis, $M_{s i l}$ is set as the lower limit value of slipping moment in friction dampers and $M_{s i 2}$ is set as the upper limit value.

Hence, the friction dampers will not slip under a slight earthquake and start to slip before the ultimate limit state of main structure. By changing $A_{s}$ from 0.0 to $1.0, M_{s i}$ basing on $A_{i}$ distribution could be obtained by (12). From [18] we can see that a $5000 \mathrm{KN}$ capacity of damper has been designed and experimented successfully. By comparison with $M_{s i}$ in this paper, the slipping moment is much smaller than that and can be considered to be achieved by controlling the axial force of bolts. However, it is worth noting that the above-mentioned distribution of slipping moment is only for Model-A. For Model-B, the slipping moment of damper in each story is the same as that of the damper in the 12th story so that the damper of each story can easily slip under earthquake.

\section{Model Analysis}

Main and damped frame periods are shown in Table III. The periods of the damped frame were obtained by rigid joints instead of damper connection (i.e., plastic-wen element).

TABLE II. SEISMIC WAVES

\begin{tabular}{|c|c|c|c|}
\hline Earthquake & PGV (m/s) & PGA $\left(\mathrm{m} / \mathrm{s}^{2}\right)$ & Time (s) \\
\hline Elcentro NS & \multirow{4}{*}{1.0} & 10.21 & \multirow{4}{*}{40} \\
\hline Tohoku EW & & 7.34 & \\
\hline Hachinohe EW & & 5.10 & \\
\hline Kumamoto EW & & 8.02 & \\
\hline
\end{tabular}

TABLE III. STRUCTURE PERIODS

\begin{tabular}{|c|c|c|}
\hline Periods & Damped structure (s) & Main structure (s) \\
\hline 1st & 1.06 & 1.56 \\
\hline 2nd & 0.35 & 0.55 \\
\hline
\end{tabular}

\section{Comparison of the Two Models}

In order to observe the seismic behavior of two models that used different distribution of slipping moment, drift, bending moment, shear force and energy dissipation of friction dampers are used as reference indexes for a fixed value of $A_{s}\left(A_{s}=0.0\right)$. Drifts of the two models under the four seismic waves are shown in Figure 7. It can be observed that each story drifts in Model-A are smaller than the ones of each story in Model-B under any seismic wave. However, according to various seismic waves, the drift reduction ratio is different. In the case of El centro NS, the maximum and minimum drift reduction ratios are $37 \%$ (5th story) and $4 \%$ (12th story), respectively. In another case of Kumamoto EW, maximum and minimum drift reduction ratios dwindle to $17 \%$ (1st story) and $2 \%$ (5th story), respectively. Despite all this, it still can be considered that for drift reduction, the distribution of slipping moment in Model-A is much more efficient than that in Model-B.

A comparison of the bending moment of the beam element in the two models is shown in Figure 8. The beam bending moment of Model-A is smaller than that of Model-B. It means the importance of the distribution of slipping moment. In the four cases, the bending moment reduction of the sub-structure is relatively more obvious than that of the upper structure.

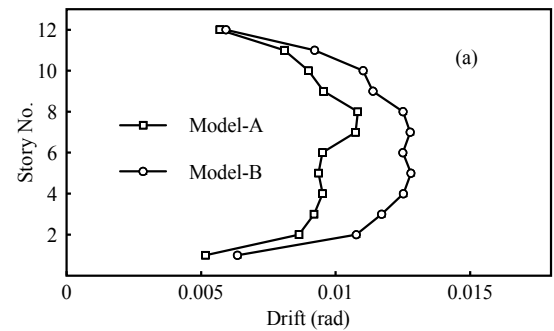

(b)

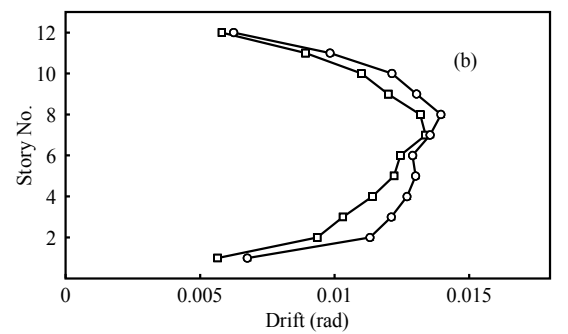

(c)

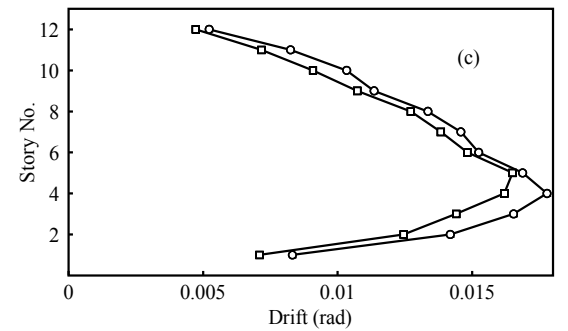

(d)

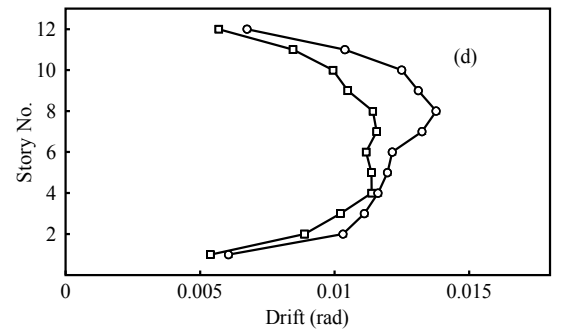

Fig. 7. Drift of each story in the two models: (a) ElcentroNS, (b) HachinoheEW, (c) KumamotoEW, (d) TohokuEW.

Because shear force of the sub-structure is larger than that of the upper structure, the bending moment of friction damper installed in the sub-structure is easy to reach the predetermined value, and then the dampers can dissipate more seismic energy. It also means that energy dissipation of friction damper installed in the sub-structure is more than that in the upper structure. Although in the case of Kumamoto EW, a part of bending moment in Model-A is almost the same with that in Model-B, as a whole, the distribution of slipping moment in Model-A is more efficient. The shear force of each story in the two models is shown in Figure 9. The reduction of shear force in Model-A exhibits the superiority of Model-A. The maximum reduction ratios in four cases are 37\% (Elcentro NS, 5th story), $22 \%$ (Hachinohe EW, 2nd story), 18\% (Kumamoto EW, 10th story), 26\% (Tohoku EW, 9th story), respectively. To compare the capacity of energy dissipation of friction damper in the two models, the percentage of total input energy dissipated by the 
dampers is shown in Figure 10 As we see the dissipated energy by the dampers in both models has exceeded the $50 \%$ of the total input energy. This means that the friction dampers have a large potential in energy dissipation. The dissipated energy in Model-A is more than that in Model-B. In the Model-A, the maximum value is about $67 \%$ in the case of Hachinohe EW. From Figures 7-10 can be concluded that the distribution of the slipping moment in dampers along the height of Model-A is more efficient.

(a)

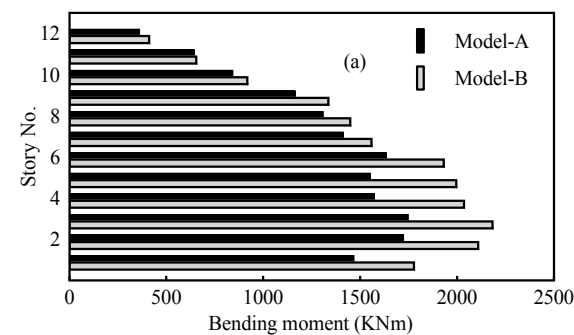

(b)

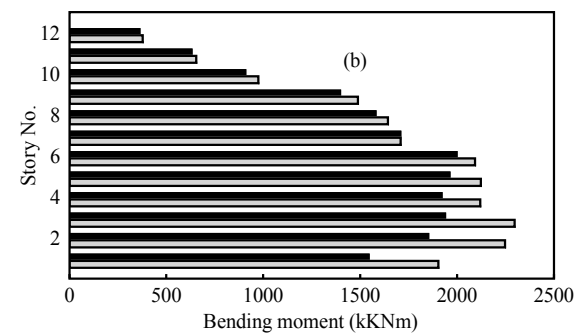

(c)

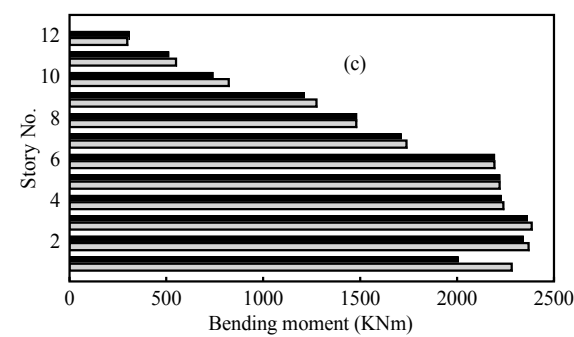

(d)

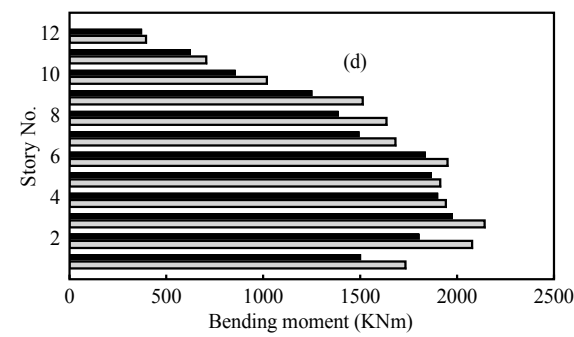

Fig. 8. Bending moment of beam in each story: (a) ElcentroNS, (b) HachinoheEW, (c) KumamotoEW, (d) TohokuEW.

\section{E. Optimal Value of Slipping Moment}

The optimal value of the slipping moment in Model-A will be discussed in this section. The normalized response values of the structure should be studied as a function of the slipping moment ratio $\left(A_{s}\right)$. The normalized drift is described by (13) in which $R_{A s=j}^{i}$ is the drift in $i$-th story when $A_{S}=j$ and $R_{A s=0}^{i}$ is the drift in $i$-th story when $A_{s}=0$.
$R_{\text {ratio }}^{i, j}=\frac{R_{A_{s}=0}^{i}}{R_{A_{s}=0}^{j}}, j=0-1$, step $=0.1, i=1-12$, step $=1$

(a)

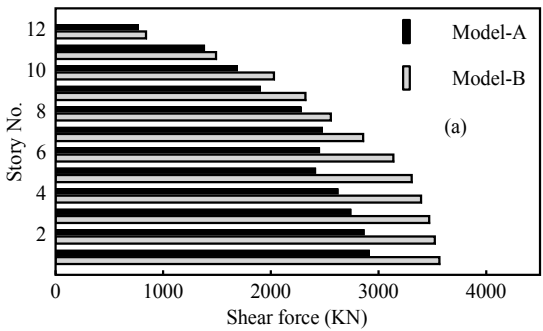

(b)
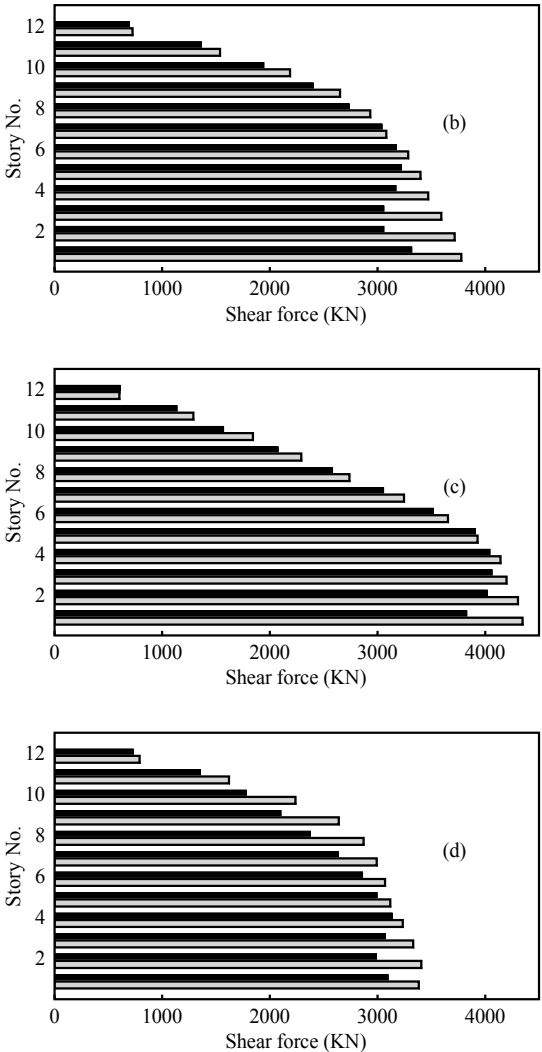

Fig. 9. Shear force of each story: (a) ElcentroNS, (b) HachinoheEW, (c) KumamotoEW, (d) TohokuEW

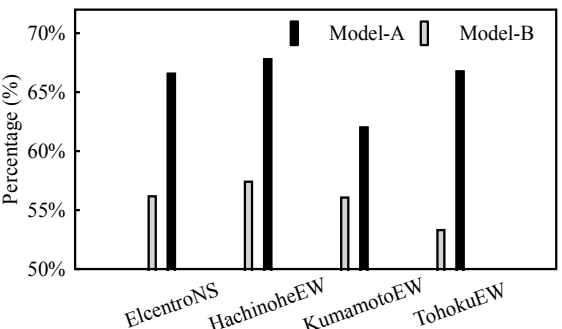

Fig. 10. Percentage of total input energy dissipated by damper

Similarly, the normalized bending moment of beam is presented by: 


$$
B M_{\text {ratio }}^{i, j}=\frac{B M_{A_{s}=j}^{i}}{B M_{A_{s}=0}^{i}}, j=0-1, \text { step }=0.1, i=1-2, \text { step }=1
$$

From Figure 11, the drift of each story expresses a different variation trend with the increasing of $A_{s}$. In the four cases, the drift of the sub-structure (white marking) increased with the increasing of $A_{s}$. However, in the cases of Elcentro NS and Kumamoto EW, the drift of the upper structure (black marking) nearly kept constant. In the case of Hachinohe EW, it kept decreasing. In the case of Tohoku EW, it firstly decreased and then increased for $A_{s}$ within the range from 0.0 to 0.6 .

(a)

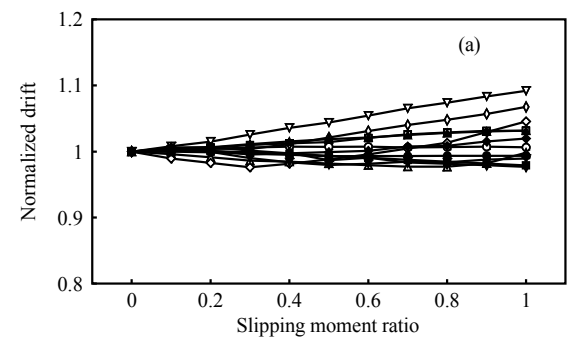

(b)

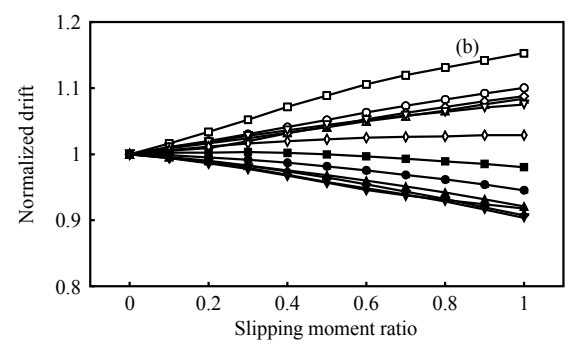

(c)

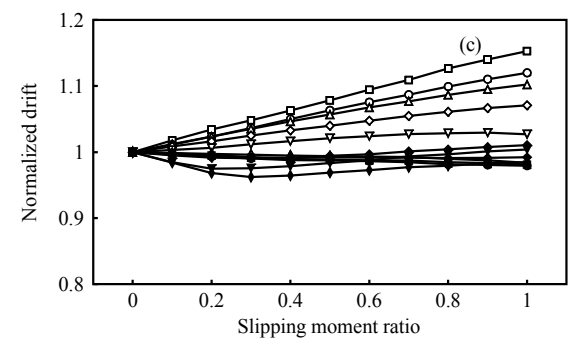

(d)

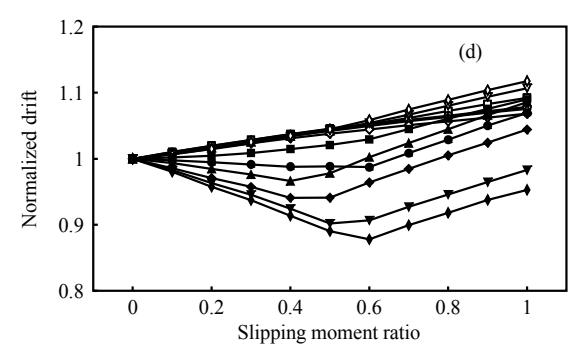

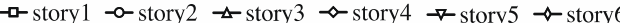

$\rightarrow$ story $7 \rightarrow$ story $8 \leftarrow$ story $9 \rightarrow$ story $10 \multimap$ story $11 \rightarrow$ story 12

Fig. 11. Normalized drift of each story in Model-A: (a) ElcentroNS, (b) HachinoheEW, (c) KumamotoEW, (d) TohokuEW.

The normalized beam bending moment shown in Figure 12 has a similar trend with the drift. However, in the case of Tohoku EW, the minimum bending moment of the upper structure can be obtained when $A_{s}=0.4$. Comparing the two Figures, it can be observed that for the dampers installed in the sub-structure, the smaller the $A_{s}$ the better. For those in the upper structure, the range of $A_{s}$ from 0.0 to 0.4 is suggested. Generally, the percentage of the total input energy dissipated by the dampers is an important index to determine an optimal value of slipping moment (Figure 13). As shown in Figure 13, more than $60 \%$ of total input energy has been dissipated by friction dampers, which is a very large value and obviously not suitable. The peak of the dissipated energy (black marking) is obtained for $A_{s}$ within the range from 0.0 to 0.4 . Sometimes, the dissipated energy does not necessarily indicate the best performance of the structure, as it is accompanied by increase in the total seismic energy [12].

(a)
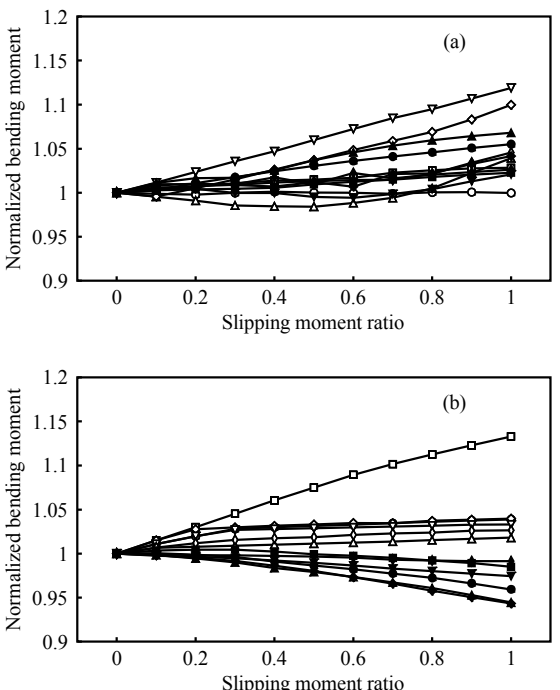

(c)

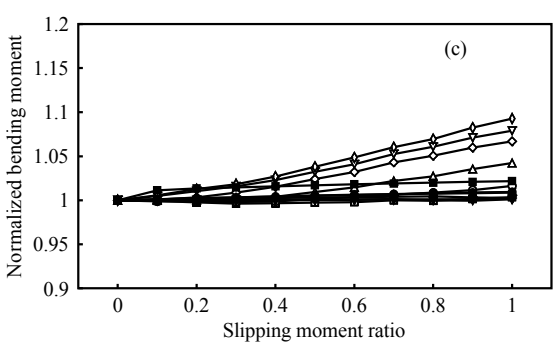

(d)

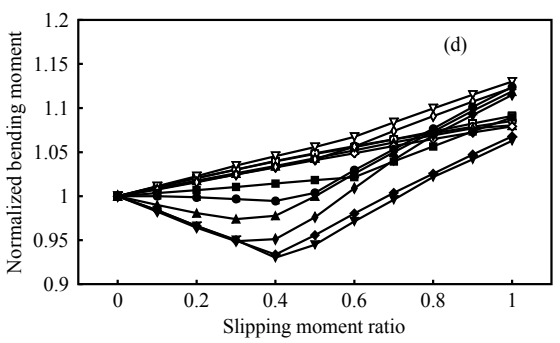

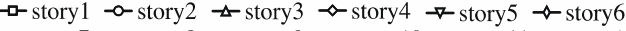
$\rightarrow$ story $7 \rightarrow$ story $8 \leftarrow$ story $9 \rightarrow$ story $10 \rightarrow$ story $11 \rightarrow$ story 12

Fig. 12. Normalized bending moment of each story in Model-A: (a) ElcentroNS, (b) HachinoheEW, (c) KumamotoEW, (d) TohokuEW. 


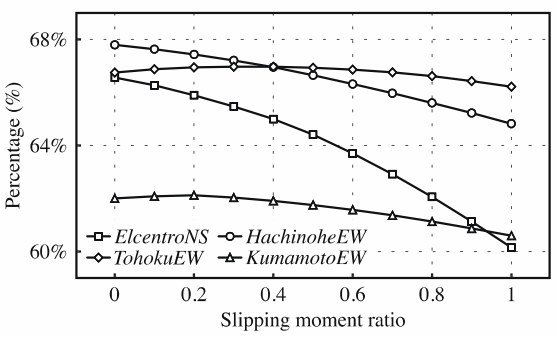

Fig. 13. The effect of slipping moment ratio on energy dissipation

\section{CONCLUSIONS}

Basing on the feature of friction damper, (i.e., displacement dependence) a concept of linkage system that could be considered as a combination of the Pall friction damper and the rotational friction damper has been presented. It can improve the capacity of energy dissipation of friction damper by increasing the rotational angle. The relationship between rotational angle and the main structure drift has been derived as a formula by trigonometric functions and the high accuracy of the formula has been verified by numerical analysis. Two models having different distribution of slipping moment along the structure height have been analyzed and compared. Analysis results demonstrated that a properly distribution of the slipping moment is necessary and the Model-A is more efficient than Model-B. In addition, the optimal value of slipping moment, (i.e. $A_{s}$ ) in Model-A has been discussed. Time history analysis results showed that for the friction damper installed in the sub-structure, the smaller the value of $A_{s}$ the better and for the upper ones, a range of $A_{s}$ from 0.0 to 0.4 is suggested. Further research is needed to verify the above conclusions. In future studies, stiffness of linkage system, intensity of seismic waves, distribution of linkage system, etc. should be factored in and the construction of linkage system should be discussed and tested by a series of experimental and numerical analyses.

\section{REFERENCES}

[1] United States Geological Survey, USGS Real-time Earthquake , available at https://www.usgs.gov/products/data-and-tools/real-timedata/earthquakes

[2] S. M. Zahraei, A. Moradi, M. Moradi, "Using pall friction dampers for seismic retrofit of a 4-story steel building in Iran", Topics in Dynamics of Civil Structures, Vol. 4, pp. 101-107, 2013

[3] A. S. Pall, C. Marsh, "Response of Friction Damped Braced Frames", Journal of Structural Engineering, Vol. 108, No. 9, pp. 1313-1323, 1982

[4] V. Ruiz, K. Walsh, M. M. Abdullah, Investigating The Energy Dissipating Properties of Passive Friction Devices, Florida State University, \&Tokyo Institute of Technology, Tokyo, Japan, 2005

[5] R. Chandra, M. Masand, S. K. Nandi, C. P. Tripathi, R. Pall, A. Pall, "Friction-dampers for seismic control of La Gardenia towers south city, Gurgaon, India”, 12th World Conference on Earthquake Engineering, New Zealand, January 30-February 4, 2000

[6] T. H. Hale, R. Pall, "Seismic upgrade of the Freeport water reservoir, Sacramento, California", 12th World Conference on Earthquake Engineering, New Zealand, January 30-February 4, 2000

[7] A. S. Pall, R. Pall, "Friction-damper used for seismic control of new and existing buildings in Canada", ATC-17-1 Seminar on Seismic Isolation, Passive Energy Dissipation and Active Control, San Francisco, USA, March 11-12, 1992
[8] B. Wu, H. Li, L. Lin, M. Shan, "Seismic retrofit of a city hall in Northeast China with frictional energy dissipators", Journal of Building Structures, Vol. 19, No. 5, pp. 28-36, 1998 (in Chinese)

[9] A. Pall, S. Vezina, P. Proulx, R. Pall, "Friction - Dampers for Seismic Control of Canadian Space Agency Headquarters", Earthquake Spectra, Vol. 9, No. 3, pp. 547-557, 1993

[10] T. H. Hale, R. T. Pall, "Seismic upgrade of the freeport water reservoir, Sacramento, California", 12th World Conference on Earthquake Engineering, New Zealand, January 30-February 4, 2000

[11] D. Shao, A. Pall, B. Soli, "Friction Dampers for Seismic Upgrade of A 14-Story Patient Tower With A 36-Foot Tall Soft-Story", 8th US National Conference on Earthquake Engineering, San Francisco, USA, April 18-22, 2006

[12] H. I. Mualla, B. Borislav, "Performance of steel frames with a new friction damper device under earthquake excitation", Engineering Structure, Vol. 24, pp. 365-371, 2002

[13] K. Jafarzadeh, M. L. Yaghin, R Sabetahd, "Evaluation pf Pall Friction Damper Performance in Near-Fault Earthquakes by Using of Nonlinear History Analysis", World Applied Sciences Journal, Vol. 20, No. 2, pp. 264-270, 2012

[14] G. S. Adithya, H. Narendra, "Performance evaluation of friction dampers under seismic loads", International Journal of Research in Engineering and Technology, Vol. 5, No. 14, pp. 10-15, 2016

[15] P. Hosseini Sarjou, N. Shabakhty, "Effect of the Improved Pall Friction Damper on the Seismic Response of Steel Frames", Engineering Technology \& Applied Science Research, Vol. 7, No. 4, pp. 1833-1837, 2017

[16] American Society of Civil Engineers, Seismic Evaluation and Upgrade of Existing Buildings, 2014

[17] Architectural Steel Structure - Theory and Design, Kajima Institute Publishing, 2007 (in Japanese)

[18] I. H. Mualla, E. D. Jakupsson, L. O. Nielsen, "Structure behavior of $5000 \mathrm{KN}$ damper", 14th European Conference on Earthquake Engineering, Republic of Macedonia, August 30-September 3, 2010 